\title{
To compare the image of door god in zhuxian town and fengxiang New Year paintings
}

\author{
Zhang Chen \\ Xi'an Academy of Fine Arts, Shaanxi, China, 710065
}

Keywords: New Year Painting; The image of Door God; Zhu xian zhen; Feng xiang; Artistic characteristics

Abstract: Most Block Printed Chinese New Year Paintings are of exaggerated image and bright colors. Due to geographical characteristics, cultural background, history, folk culture, New year paintings from each region are also showing a different style. Wooden block printed Door Gods' image is an important species, but also first appeared in Chinese new year paintings. In this papar, we will compare the image of a pair of Door Gods from two different towns which are Zhu xian and Feng xiang. We will compare the artistic characteristics graphically from creation method, Character modeling, colours, current situation of protection. And we will propose the suggestion for the better protection and future development of the Block Printed Chinese New Year Paintings, so that we can carry forward, develop and expand our traditional culture.

\section{The general situation of Block Printed Chinese New Year Pictures from Zhu xian and Feng xiang}

Zhuxian town of Kaifeng and Feng xiang town of Baoji are two important places of Block Printed Chinese New Year Paintings. The paintings in both places have unique colors and styles. New Year paintings of Zhu xian town first emerged in the BeiSong dynasty. According to " Beautiful Dream DongJing ", near the spring festival, selling Door gods, Zhong kui, Peach Wood Charms Against Evil and money door blunt donkey, head back deer horse, tianxing stickers are everywhere along the street in Dongjing city". It can be seen that the printing and sales of Dongjing New Year paintings were unprecedented at that time. The New Year paintings features are full composition, with rough and simple lines, exaggerated modeling, fresh and gorgeous colors. As a major genre of Chinese folk New Year paintings, Bao ji Feng xiang Block Printed New Year paintings also play an important role in Chinese traditional culture. The images in fengxiang New Year paintings are from many historical allusions and thematic patterns of myths and legends. Most of the shapes are solid and simple, and the combination forms are lively and vivid, which can give visitors a larger space for artistic imagination. The image of Door god is an important variety in New Year paintings, and also the earliest art form of New Year paintings. In the past, people pasted their Gods on the doors against evil spirits and protect the family and residence, to help the utilitarian and to be auspicious, they were one of the most popular protective gods among the people. There are many images and types of Door gods, most of them are heroes in fairy tales or history. This paper compares a pair of Door gods in Zhu xian town's New Year paintings, which are 
Zhao gongming and RanDengDaoRen, and a pair of door gods in Fengxiang New Year paintings, which are QinQiong and JingDe.

\subsection{The image of the Door Gods from Zhu xian town}

There are about 20 kinds of Door gods in Zhu xian town New Year paintings. But the most important images are RanDengDaoRen and Zhao GongMing. Generally speaking, most of the Goor gods' paintings are based on Qin Qiong Jing De, but this pair of door gods in Zhu Xian town adopts RanDengDaoRen and ZhaoGongMing (both of them are the characters in The Investiture of the Gods). RanDengDaoRen helped against King Zhou of Shang dynasty by King Wu of Zhou dynasty. Zhao gongming assisted King Zhou to resist the zhou army. They are equal in strength, so folk painted it as a pair of Door gods. On The Investiture of the Gods, ZhaoGongMing was named "jin long ru yi zheng yi long hu xuan tan zhen jun", So it's also called the god of fortune.
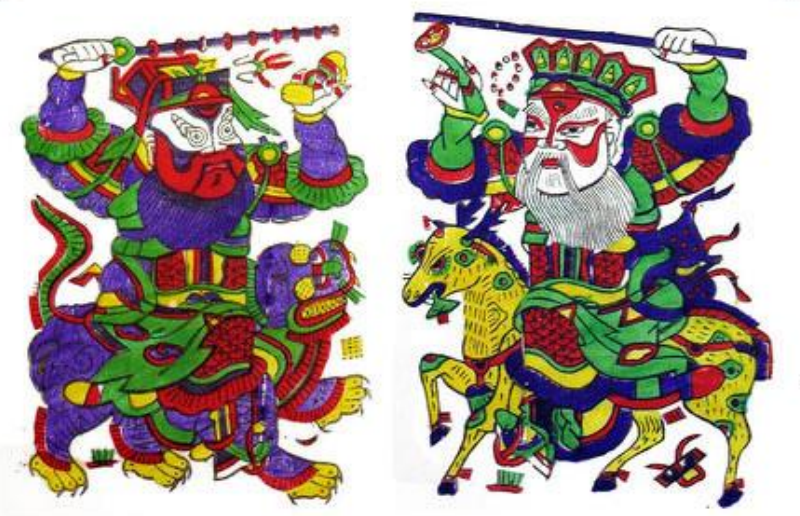

\subsection{The image of the Door Gods from Feng xiang}

Fengxiang New Year paintings has a Door god riding on the horse Qin Qiong Jing De, which is very similar to this Door god of zhu xian town. Comparing two pairs of Door gods, there are the following differences and similarities:

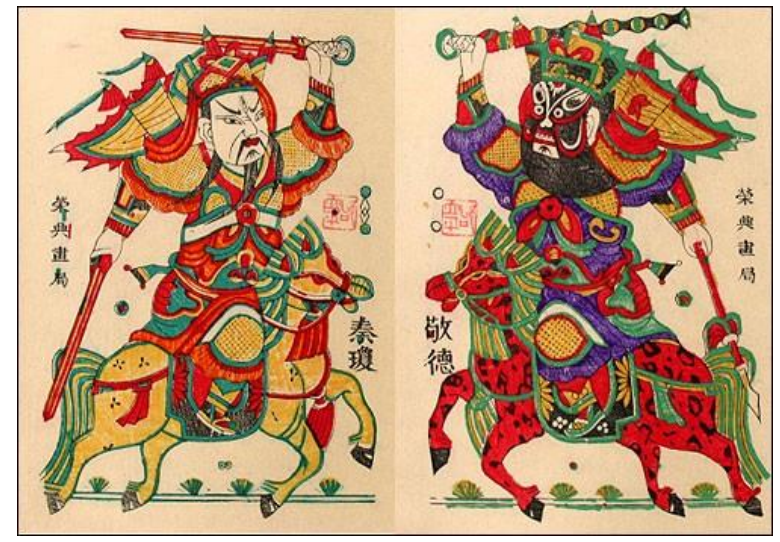

\section{Similarities and differences of the Door Gods' image}

Above all, both are New Year paintings, colorific overprint and become, do not add manual fill dye. Secondly, in terms of their characters' movements, they all have their own mounts, have their own weapons in their hands and move upward. In zhu xian town's New Year painting, zhao 
gongming rides a tiger, wielding an iron whip with his right hand, and makes the golden horseshoe scissors and sea beads with his left hand. Burning lamp road person crosses sika deer, hold qiankun ruler, two people mount respectively for tiger, deer, hence again call "tiger deer Door god". In fengxiang's New Year painting, qin qiong and jing dejun rode horses. Qin qiong held the mace in his left hand and carried the gun in his right hand. With the whip in the right hand and the gun in the left. This is one of their similarities. Third, the performance in color. Two Door gods in the basic colors are black, red, yellow, green, such five kinds of color, fengxiang New Year painting more than a golden, and color hue is very close, just slightly different in the color distribution of the, bold colour orientation using complementary color photograph collocation, colorful, purple and white, red and green phase, middle hook to chalk line of dignified, strong contrast, reflects the Chinese folk atmosphere and unconstrained. The fourth similarity is shown in the composition. Although the size of the two works is different, they are all full and symmetrical, which conforms to the basic characteristics of the Door god. Fifth, in the figure of the figure, zhu xian town New Year paintings is a red face, a white face, fengxiang New Year paintings is a black face and a white face, both formed a sharp contrast, the two New Year paintings of the Door gods do not paint powder, there is no ogle, the performance is a hero of integrity. Finally, the lines of zhu xian town and fengxiang New Year paintings are very rough and simple, with lines carved with Yin and Yang and strong contrast. The technique of ancient figure painting is particularly outstanding in the aspect of clothing lines, with thick, pure and thick lines, rich in game, and unique rustic, thick and robust demeanor of the northern people. In addition to these similarities, there are many differences. The most striking difference is that in the shape of the image, the image of the characters in juxian town is quite dramatic, and it's a small, small, and it has a lot of Chinese ancient characters in the engraving, and the characters are so simple, they're so thick, they're so thick, they have a lot of pictures of the heroes, and they have the same basic, natural, unsophisticated, plain, unearthy, unearthy, simple, unsophisticated, unsophisticated, primitive, primitive, ethnic art style. Fengxiang New Year paintings and characters although there are exaggerated, but the basic consistent with the proportion, and combined with fengxiang New Year paintings, since there has always been based on the northwest countryside, its creators are derived from civil limner and folk artists, and consumer groups are mainly for the general public, northwest northwest uninhibited personality also infected with the creation of the New Year paintings, its energetic, heavy style. For example, the lines and strokes of the Door gods are very close to the style of the temple murals. The content of gu yu painting is relatively rich, making the northwest rural plain folk customs true portrayal. In addition, the origin place of New Year paintings in NanXiaoLi traffic inconvenience, rarely by the impact of external art and influence, so that it retained its unique folk characteristics. The characters and animals in the Door gods of juxian town are opposite to each other, while the characters and animals in the Door gods of fengxiang turn their backs and their heads are opposite to each other. This style is very unique, and is rarely seen in other Door gods across the country. From the whole painting, zhu xian town New Year paintings slightly rough, but more exaggerated bold and bold. And fengxiang New Year paintings than zhuxian town, but a little more fine print effect is also clear. In history, due to a number of reasons, zhuxian town wood engraving New Year painting was forced to appear interrupt; For over 500 years, fengxiang New Year paintings have been developed in an orderly way without interruption. In different historical periods, there were innovations, and even new works appeared during the Cultural Revolution. After several generations of restoration, great progress has been made in protecting and inheriting the New Year paintings in places like zhuxian town and fengxiang, which have been publicized at home and abroad and achieved a lot. However, its survival status is still endangered. I think these places are still worth our attention. 


\section{Inheritance and protection of Block Printed Chinese New Year Pictures}

First of all, with the development of society and the progress of modern printing technology, offset New Year paintings are everywhere. Offset New Year paintings cost low, do not need to invest too much manpower, and printing speed, quantity, content closer to real life, in the price, also substantially lower than traditional New Year paintings, so quickly occupied the market, replaced the status of folk New Year painting. In addition, people's awareness of money has increased, the pace of social life has quickened, and the taste of the year has become less and less. A lot of folk art previously seen in the streets has gone extinct, while the phenomenon of buying New Year paintings has gradually disappeared when people go shopping for New Year paintings. This makes the production space of traditional New Year paintings smaller and smaller, the New Year paintings that once flourished are in an embarrassing situation that no one care about them.

Secondly, with the death of old artists who were skilled in wood engraving New Year paintings, the folk art was regarded by the young as a laborious and thankless industry, so they gave up traditional folk handicrafts and became keen on modern art. The people who make a living by this art, but also because of the forced life, one after another, so the folk wood engraving New Year paintings presents a kind of situation. The inheritance of woodblock New Year paintings becomes the main problem.

Nowadays, there are more and more calls for the protection of folk art. In the case that the folk art is dying out even faster than the rescue, how to effectively protect the traditional wood engraving New Year paintings has become a common problem we should face. The most important thing is the protection of "people". People here refer to folk artists and their inheritors. And inheritance have not only refers to the makers of the performers of traditional arts and traditional crafts, it should be extended to more attention to folk art, interested in the folk art of the experts and scholars such as indirect inheritance, descendants of these two should be mutual cooperation, under the guidance of specialized organization, jointly bear the burden of inheriting folk art.

Second, we should pay attention to the protection of intellectual property rights of folk art. We should distinguish folk art from vulgar and uncultured things. It should also be noble and elegant. More importantly, the legitimate rights and interests of folk artists should be protected. After all, folk art is not a tool for those cultural departments that folk artists serve for free. It should be an independent art category with its own way of existence.

Finally, we should also realize the importance of cultivating people's interest in folk culture, and publicize the folk art so that the folk art, which has been shrouded in dust for many years, can be noticed again. The origin place of folk art is folks, and it should eventually return to folks, just as flowers only live in the soil, it will have long life, and once placed in a vase, it will soon wither away.

\section{References}

[1] Wang shucun, <the development of Chinese New Year paintings>, Tianjin People's Fine Arts Publishing House, 2005

[2] Xu yiyi, <wu hua gong qiao -- exploration and research of traditional material culture>, Tianjin People's Fine Arts Publishing House, 2005

[3] Ma shutian, <the Chinese god world>, Jiuzhou press, 2002

[4] Bo songnian, <Chinese door god painting>, lingnan art press, 1998

[5] Xiang yunju, <human oral and intangible heritage>, ningxia people education press, 2004

[6] Wang zijin, < door sacrifice and worship of door gods>, SDX Joint Publishing Company, 1994 